\title{
Changes in Total Protein Concentration Due to Fluid Removal During and Shortly after Hemodialysis
}

\author{
John T. Daugirdas \\ University of Illinois College of Medicine at Chicago, Chicago, IL, USA
}

\section{Keywords \\ Protein concentration · Hemodialysis · Volume overload}

\begin{abstract}
Background: Changes in plasma volume during hemodialysis are complex and have been shown to depend on the rate of fluid removal and the degree of fluid overload. We examined changes in total protein concentration during and shortly after a dialysis treatment in archived data from the HEMO study. Methods: During follow-up months 4 and 36 of the HEMO study, additional blood samples were obtained during a typical dialysis session at 30 and $60 \mathrm{~min}$ after dialysis. In 315 studies from 282 patients where complete data were available, we calculated the concentration change in total protein and compared it to the modeled change in both total body water and extracellular fluid space as derived from 2-pool urea kinetic modeling. Results: The mean postdialysis modeled urea volume (V) was $31.1 \pm 6.18 \mathrm{~L}$. Mean fluid removal was $2.76 \pm 1.27 \mathrm{~kg}$, over a session length of $207 \pm 28 \mathrm{~min}$. The ratio of predialysis $V$ to postdialysis $V$ averaged $1.090 \pm 0.040$. The mean TP ratios (post/pre) at 0 ,
\end{abstract}

\section{KARGER}

() 2018 S. Karger AG, Basel

E-Mail karger@karger.com

www.karger.com/ajn
30, and 60 min postdialysis averaged $1.121 \pm 0.070$ (SD), $1.091 \pm 0.090$, and $1.091 \pm 0.086$. The dialysate to serum sodium gradient, studied in a different group of treatments where this information was available, had no impact on these findings, nor did the length of the interdialytic interval. Conclusions: On average, after equilibration, the change in plasma volume due to fluid removal is similar to the modeled change in total body water (urea space), irrespective of dialysate to serum sodium gradient. This supports previous observations that during dialysis with ultrafiltration, plasma volume contracts to a lesser degree than the interstitial volume and that some fluid may be removed from spaces other than the extracellular fluid.

(c) 2018 S. Karger AG, Basel

\section{Introduction}

The conventional wisdom based on early isotopic studies [1] and later bioimpedance data [2-4] suggested that fluid removal during hemodialysis was taking place primarily from the extracellular fluid (ECF) space. In a 
normally hydrated subject, ECF is thought to be about $1 / 3$ of the volume of total body water. Not all studies were consistent in this regard, however, and some analyses found that the amount of fluid removed during dialysis exceeded measured changes in the ECF $[5,6]$. In the earliest of the initial group of studies, it was suggested that the source of fluid removed during dialysis depended on the sodium gradient between dialysate and the predialysis serum sodium [1], favoring removal from the intracellular space when the dialysate sodium was high versus expansion of the intracellular space when dialysate sodium was low.

We realized that the increases in serum total protein during dialysis and during the early postdialysis interval (to minimize the impact of plasma refilling), might give some indication about the size of the space from which fluid was being removed during dialysis, and accordingly, we compared the ratio of increases in total protein to the ratio of changes in the calculated total body water as well as calculated ECF volume.

Examination of the changes in serum total protein during dialysis relative to changes in body water spaces in treatments with different degrees and directions of sodium gradient allowed us to test previous observations that the dialysate to serum sodium gradient might affect the volume from which fluid was removed [1].

\section{Materials and Methods}

In the HEMO Study [7], which followed approximately 1,800 patients over a several year period, pre- and postdialysis blood samples were analyzed by a central laboratory on a monthly basis. Additional blood samples were obtained $30 \mathrm{~min}$ after dialysis, and in a subset, $60 \mathrm{~min}$ after dialysis, at months 4 and 36 of follow-up. The dialysis sessions studied at months 4 and 36 were typical for each patient's prescription, the only change being the additional number of blood samples drawn. These blood samples included serum total protein values.

In the HEMO study, postdialysis urea distribution volume, which is believed to be similar to total body water, was calculated in each patient using 2-pool urea modeling $[8,9]$. The calculation of urea volume was based on estimates of dialyzer clearance validated using both in vitro and in vivo clearance measurements [10-12].

An archived dataset from the NIDDK Repository of HEMO study laboratory analyses and dialysis treatment parameters at follow-up months 4 and 36 was used for these analyses. Although data was available on more than 1,600 intensively studied dialysis sessions, we elected to limit the analysis to a smaller number of sessions in which blood samples were available not only at $30 \mathrm{~min}$ after the end of a dialysis session but also at $60 \mathrm{~min}$. Three hundred and twenty-five such sessions were available in which there were no missing data, and 10 sessions were deleted because values of total protein or total protein ratios were more than $3 \mathrm{SD}$ outside of the group range. In the 315 dialysis sessions studied, 282 unique patients were represented. Because the 2 dialysis sessions for the 33 patients studied twice (during months 4 and 36 years of followup) were separated by 32 months, each dialysis session was treated as a unique event in the statistical analyses. Of the 315 dialysis sessions analyzed, 138 were in men and 177 in women.

We also looked at a larger group of dialysis sessions studied during follow-up months 4 and 36, where a 60 min postdialysis blood sample was not necessarily available but where both dialysate and serum sodium levels were measured. In four hundred and ninety-three such sessions (in 488 unique patients) total protein, nominal dialysis solution sodium, and measured preand postdialysis serum sodium values were available. In this group, we excluded a substantial group of patients in whom variable dialysate sodium was used. Only patients being dialyzed at a fixed, constant dialysate sodium concentration were included.

The estimated change in total body water during dialysis was calculated as (Vurea-post + weight change)/V-urea post, where Vurea post was the 2-pool postdialysis urea distribution volume, as calculated by urea kinetics [9-12]. The estimated change in ECF was calculated as (Vurea-post/3 + weight change)/(Vurea-post/3). The change in serum total protein was computed as a ratio, comparing the postdialysis, 30-min postdialysis, or 60-min postdialysis value to the predialysis value. Values for urea, total protein, and sodium were all measured by the HEMO study central laboratory, as previously described $[7,8]$.

\section{Results}

The characteristics of the 315 dialysis sessions are presented in Table 1. This included a mix of dialysis sessions prescribed according to the high-dose arm and low-dose arm, and included patients randomized to both the highand low-flux dialyzer arms of the study. The mean predialysis and postdialysis weights of these patients were 71.8 and $69.0 \mathrm{~kg}$, respectively, with a mean weight loss of $2.76 \pm$ $1.27 \mathrm{~kg}$. The mean postdialysis urea volume was $31.1 \mathrm{~L}$, and the mean calculated postdialysis ECF volume, assuming a postdialysis ratio of ECF to total body water of 1:3, was $10.2 \pm 2.04$. When the weight change was added to both the postdialysis urea distribution volume, presumably the total body water and the presumed postdialysis ECF, the ratio of pre to postdialysis volume space averaged $1.09 \pm 0.040$ for total body water and $1.27 \pm 0.12$ for the ECF.

The mean and median values of serum total protein during the course of dialysis for this subset of 315 patients are shown in Figure 1. The values shown at $1 \mathrm{~h}$ and postdialysis were based on blood drawn after a 20 -s slow flow period to minimize any possible effects of access recirculation. As shown, there was a substantial drop in serum 


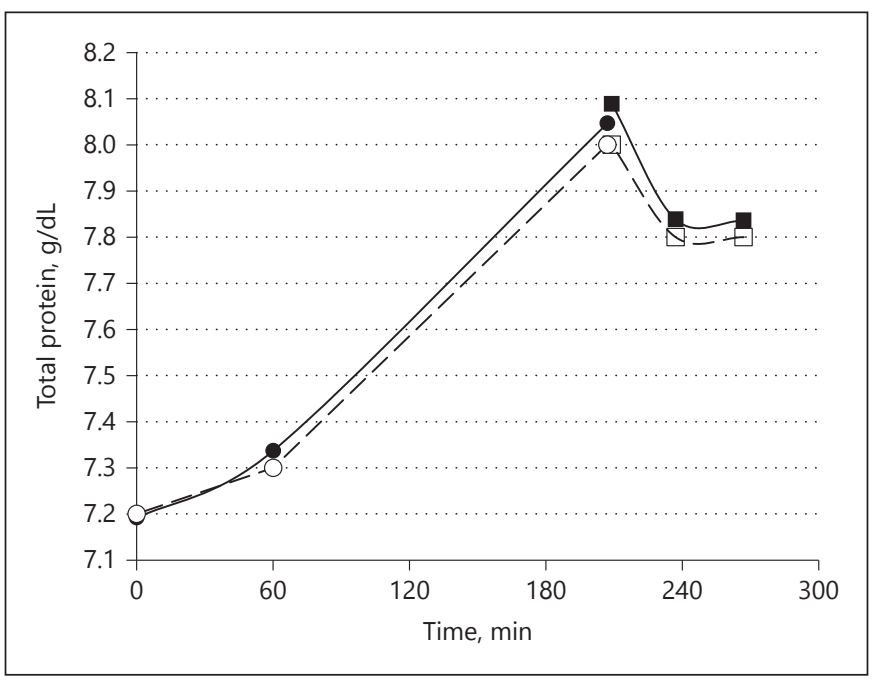

Fig. 1. Total protein levels predialysis, at $1 \mathrm{~h}$, postdialysis, and 2, 30, and 60 min postdialysis ( $n=315$ treatments, 282 unique individuals). Solid symbols are mean values and open symbols are medians.

Table 1. Patient and treatment characteristics $(n=315)$

\begin{tabular}{lc}
\hline & Mean (SD) \\
\hline Age, years & $55.8(15.6)$ \\
Body weight postdialysis, kg & $69.0(15.0)$ \\
URR, \% & $71.2(6.44)$ \\
Blood flow rate, mL/min & $333(63)$ \\
Dialysate flow rate, mL/min & $639(124)$ \\
Session length, min & $207(27.7)$ \\
Serum total protein (TP, predialysis), g/dL & $7.19(0.635)$ \\
Serum total protein (TP, postdialysis), g/dL & $8.04(1.003)$ \\
Serum total protein (TP, 30 min post), g/dL & $7.83(0.866)$ \\
Serum total protein (TP, 60 min post), g/dL & $7.84(0.848)$ \\
Ratio TP-post/TP-pre & $1.121(0.070)$ \\
Ratio TP-post 30/TP-pre & $1.091(0.090)$ \\
Ratio TP-post 60/TP-pre & $1.091(0.086)$ \\
Weight change (fluid removed), kg & $2.76(1.27)$ \\
Modeled urea volume predialysis (Vurea-pre), L & $33.9(6.66)$ \\
Modeled urea volume postdialysis (Vurea-post), L & $31.1(6.18)$ \\
Ratio of Vurea-post/Watson V & $0.89(0.11)$ \\
Ratio Vurea-pre/Vurea-post & $1.090(0.040)$ \\
Modeled ECF predialysis, L & $13.0(2.70)$ \\
Modeled ECF postdialysis, L & $10.2(2.04)$ \\
Ratio ECF-pre/ECF-post & $1.27(0.122)$ \\
Ratio (Vurea-pre/Vurea-post)/(TP-post 30/TP-pre) & $1.004(0.072)$ \\
Ratio (ECF-pre/ECF-post)/(TP-post 30/TP-pre) & $1.169(0.107)$ \\
\hline &
\end{tabular}

total protein level in the first $30 \mathrm{~min}$ after dialysis had concluded, presumably due to the effects of plasma refilling. There was no significant difference in serum total protein concentration at 60 min postdialysis compared to the $30 \mathrm{~min}$ postdialysis time point.
The ratios of postdialysis total protein postdialysis to the predialysis value averaged $1.121 \pm 0.070,1.091 \pm$ 0.090 , and $1.091 \pm 0.086$ at time points 0,30 , and $60 \mathrm{~min}$ after the end of dialysis respectively. The ratio of pre to postdialysis volume space for urea distribution volume $(1.090 \pm 0.40)$ was significantly different from the total protein post/pre ratio at the immediate end of dialysis $(p<0.001)$ but was not significantly different from the post/pre total protein ratios measured 30 or $60 \mathrm{~min}$ after dialysis ( $p=0.73$ and 0.69 , respectively). In contrast, the pre to postdialysis ECF space ratio, $1.27 \pm 0.122$ was significantly higher than the total protein post/pre ratio at time points 0,30 , and $60 \mathrm{~min}$ postdialysis. The ratio of 30 min postdialysis to predialysis total protein is shown plotted against the ratio of pre to postdialysis urea distribution volume in Figure 2.

To determine if the duration of the preceding interdialytic interval might affect the degree of plasma volume contraction relative to change in urea space, we compared results in patients that were obtained after the weekend (dialyzed Monday or Tuesday) with those around a dialysis session given Wednesday through Saturday. Results are shown in Table 2. As expected, the fluid removed (weight change) was greater ( 3.0 vs. $2.6 \mathrm{~L}, p=0.0084$ ), while the dialysis session length was not significantly different. However, the ratio of $30 \mathrm{~min}$ postdialysis to predialysis total protein divided by the ratio of predialysis to postdialysis urea volume was very close to 1.0 after both 2 - and 3 -day interdialytic intervals, and these ratios were not significantly different from each other.

Because there may be some loss of total protein during high-flux dialysis, we also analyzed patients assigned to low-flux and high-flux dialysis separately. Results are presented in Table 3. There was a slight, but significant effect of flux assignment on the ratio of the serum total protein $30 \mathrm{~min}$ after dialysis to predialysis total protein, to the estimated ratio of predialysis to postdialysis urea distribution volume. In the low-flux group, the value was $1.010 \pm 0.067$, whereas in the high flux group, the ratio was $0.991 \pm 0.074, p=0.021$.

Results from the group of dialysis sessions, where nominal dialysis solution sodium and measured pre- and postdialysis serum sodium values were available are shown in Table 4 and in Figures 3 and 4 . The dialysis sessions were divided up into 3 groups based on the dialysate to predialysis serum Na gradient. As shown in Table 4, the ratio of serum total protein $30 \mathrm{~min}$ after dialysis to serum total protein measured predialysis was very similar to that of the initial patient group, and these ratios were very similar to the ratio of predialysis to postdialysis urea volume. Figure 3 shows 
Fig. 2. Ratio of predialysis urea volume to postdialysis urea volume on the horizontal axis versus the ratio of total protein measured $30 \mathrm{~min}$ after dialysis to total protein measured predialysis ( $n=315$ treatments, 282 unique individuals).

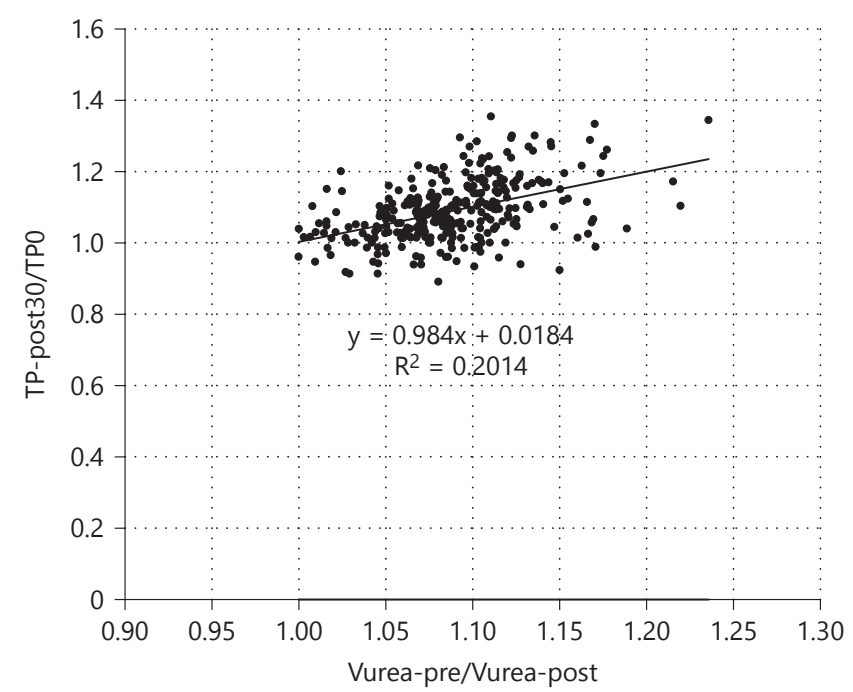

Table 2. Effect of antecedent interdialytic interval

\begin{tabular}{lccc}
\hline & 2-Day & 3-Day & $p$ value \\
\hline Number & 223 & 92 & 0.57 \\
Postdialysis weight, kg & $68.4(14.7)$ & $69.5(15.7)$ & 0.71 \\
Vurea-post, L & $31.0(6.11)$ & $30.8(6.22)$ & 0.0084 \\
UFvol (weight change), kg & $2.60(1.19)$ & $3.00(1.20)$ & 0.36 \\
Session length, min & $207(28)$ & $210(28)$ & 0.12 \\
Total protein predialysis (TP), g/dL & $7.23(0.64)$ & $7.10(0.58)$ & 0.11 \\
TP-post30/TP-pre & $1.084(0.088)$ & $1.102(0.092)$ & 0.0029 \\
Vurea-pre/Vurea-post & $1.084(0.038)$ & $1.099(0.041)$ & 0.74 \\
(TPp30/TPpre)/(Vpre/Vpost) & $1.000(0.071)$ & $1.003(0.071)$ & \\
\hline
\end{tabular}

Table 3. Effect of assignment to high-flux versus low flux dialyzer use

\begin{tabular}{lccc}
\hline & Low-flux & High-flux & $p$ value \\
\hline Number & 157 & 158 & \\
Postdialysis weight, kg & $70.2(15.4)$ & $67.3(14.5)$ & 0.10 \\
Vurea-post, L & $31.0(6.57)$ & $30.9(5.69)$ & 0.84 \\
UFvol (weight change), kg & $2.79(1.14)$ & $2.65(1.27)$ & 0.32 \\
Total protein predialysis (TP), g/dL & $7.14(0.67)$ & $7.24(0.58)$ & 0.15 \\
TP-post30/TP-pre & $1.103(0.087)$ & $1.076(0.090)$ & 0.0096 \\
Vurea-pre/Vurea-post & $1.091(0.037)$ & $1.086(0.041)$ & 0.194 \\
(TPp30/TPpre)/(Vpre/Vpost) & $1.010(0.067)$ & $0.991(0.074)$ & 0.021 \\
\hline
\end{tabular}

that the gradient between dialysis solution sodium and predialysis serum sodium had a marked impact on the postdialysis serum sodium. Figure 4 illustrates the lack of effect of sodium gradient on the ratio of the change in total protein to the change in calculated urea distribution volume.

Total Protein Concentration and Volume Removal in Hemodialysis
Because it was possible that changes in serum composition due to dialysis might be altering the laboratory measurement of total protein, we also examined the relationship between dialyzer inlet and outlet concentration in total protein in blood samples taken at $1 \mathrm{~h}$, which were 
Table 4. Effect of dialysate sodium vs. predialysis serum $\mathrm{Na}(n=493)$

\begin{tabular}{llcl}
\hline Units & Dialysate: serum Na gradient*, mM & \\
\hline Na gradient range*, mM & -25 to -3 & -2 to +2 & +2 to 25 \\
Number of cases, $n$ & 79 & 201 & 213 \\
Predialysis serum Na, mmol/L & $144(2.89)$ & $139(1.62)$ & $135(2.76)$ \\
Postdialysis serum Na, mmol/L & $142(3.98)$ & $141(3.77)$ & $140(3.54)$ \\
Post minus predialysis serum Na, mmol/L & $-1.70(4.10)$ & $1.01(3.56)$ & $4.70(3.89)$ \\
Dialysate Na, mM & $138.3(4.11)$ & $139.7(1.38)$ & $141.9(4.01)$ \\
Dialysate Na minus predialysis serum Na, mM, median & -4 & 0 & 6 \\
UFvol (weight change), kg & $2.60(1.23)$ & $2.87(1.27)$ & $3.11(1.32)$ \\
Vurea-post, L & $31.5(6.12)$ & $30.7(5.58)$ & $31.7(6.78)$ \\
Total protein predialysis (TP), g/dL & $7.30(0.60)$ & $7.25(0.59)$ & $7.26(0.70)$ \\
TP-post30/TP-pre & $1.080(0.079)$ & $1.094(0.092)$ & $1.088(0.092)$ \\
Vurea-pre/Vurea-post & $1.084(0.050)$ & $1.094(0.041)$ & $1.100(0.041)$ \\
(TPp30/TPpre)/(Vpre/Vpost) & $1.009(0.081)$ & $1.005(0.074)$ & $1.016(0.075)$ \\
\hline
\end{tabular}

* The sodium gradient is computed as nominal dialysis solution sodium minus the predialysis serum sodium. This assumes that Donnan effects fully cancel the increase in plasma water sodium due to plasma protein concentration; this is a simplification, as the effects do not quite balance.

obtained at full blood flow without altering the ultrafiltration rate. The plasma flow rate was computed as $0.67 \times$ $0.93 \times \mathrm{Qb}$, and the outflow rate was computed as the inflow rate minus Qf, the ultrafiltration rate (calculated from the change in weight and the dialysis session length). The results are shown in Figure 5. The median TPR outlet to inlet ratio was $1.086 \pm 0.049$ (median 1.081) and the mean plasma water inflow to outflow ratio was $1.070 \pm$ 0.033 (median) 1.067. The TPR ratio was significantly greater ( $p<0.001$ by paired $t$ test). The 2 ratios are shown plotted against one another in Figure 5.

\section{Discussion}

After an equilibration period of 30-60 min postdialysis, the percent decrease in plasma volume, as inferred from the increase in serum total protein, was similar to the modeled change in urea distribution volume, a surrogate measure for total body water. If water were being drawn only from the ECF space during ultrafiltration in the course of hemodialysis and if the change in plasma water reflected the change in ECF volume, we would have expected that the decrease in plasma volume to be substantially higher. For example, if we assume that postdialysis, when the patient is at a relatively "dry" condition, the ECF is about $1 / 3$ of the total body water in size, then the average estimated postdialysis ECF volume in our patients would be about $10 \mathrm{~L}$ (mean postdialysis total body

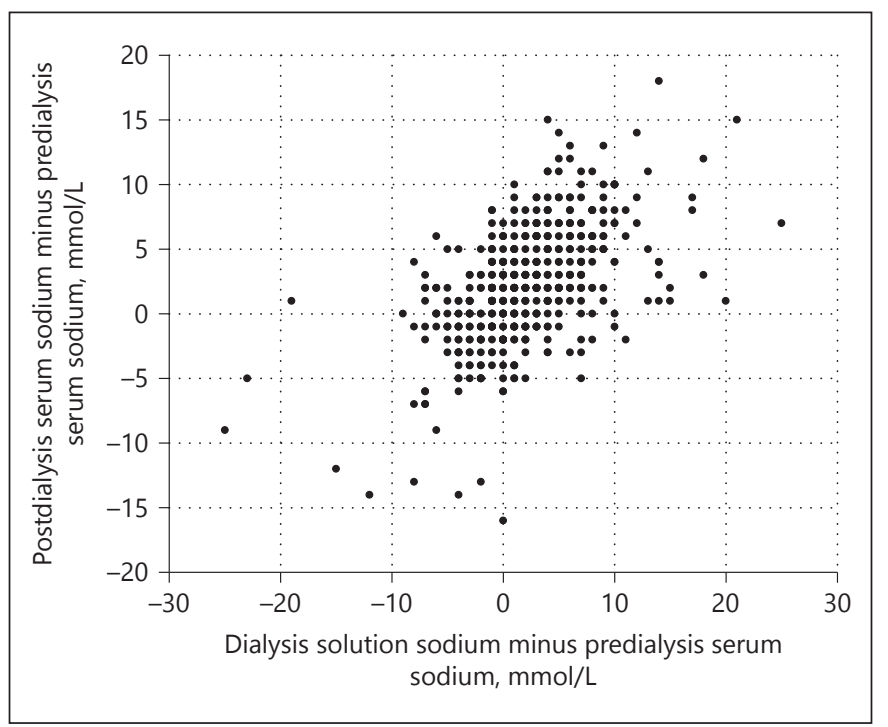

Fig. 3. Dialysis treatments in which both total protein and serum and dialysate sodium were measured ( $n=493$ treatments, 488 unique individuals). The sodium gradient, as dialysate minus predialysis serum, is plotted on the horizontal axis, and the postdialysis minus predialysis serum $\mathrm{Na}$ is plotted on the vertical axis.

water (urea space) in these patients the value being about $30 \mathrm{~L}$ ). Removal of the approximately $2.8 \mathrm{~L}$ of water, on average, would give a predicted predialysis ECF of $12.8 \mathrm{~L}$, and a ratio of predialysis ECF to postdialysis ECF of about $12.8 / 10$ or 1.28 ; If the plasma volume and ECF were contracting at the same rate, one would then have expected a 
concomitant $28 \%$ or so increase in the serum total protein concentration. If anything, immediately after dialysis, the increase in total protein should have been higher than the $28 \%$ predicted due to incomplete plasma refilling from the ECF at the immediate postdialysis time point. This did not happen, and the increase in serum total protein (after a period of postdialysis equilibration) was only 9\%, similar to the decrease in calculated urea volume. If the plasma and interstitial volumes were contracting to the same degree during fluid removal by hemodialysis, these findings would suggest that fluid is being removed from a space larger than the ECF, and in fact, from a space similar in size to the total body water.

There are, however, major difficulties with the above simplistic analysis. Such an analysis depends on the assumption that the same percentage of fluid is being removed from the plasma volume as from the interstitial volume during ultrafiltration. We know this is not the case. For example, Lopot et al. [13] identified 4 patterns of plasma volume decrease during ultrafiltration associated with hemodialysis, and in one of the patterns, plasma volume decreased only minimally or not at all, despite substantial ultrafiltation. Koomans et al. [14] examined the change in plasma volume in relation to the measured interstitial fluid volume, and found that when interstitial fluid volume was high, the decrement in plasma volume, as a percent of the ultrafiltered volume, was reduced. On examining the scatter of points in Figure 2, there does appear to be a relatively small minority of patients in whom the change in total body water is substantial, but in whom the increase in total protein is quite small. Whether these data points represent laboratory variation or a sub-population of so-called "flat-liners" is impossible to determine from the HEMO dataset in which the degree of fluid overload was not measured.

The idea that all of the fluid removed during ultrafiltration in the course of hemodialysis is from the ECF may not be completely correct, as reviewed in the introduction. For example, Ozturk et al. [15] looked at changes in both intracellular fluid (ICF) and ECF using multifrequency bioimpedance and found that about $1 / 3$ of the removed fluid came from the putative intracellular space. Quite probably, most, but perhaps not all, of the fluid being removed by ultrafiltration during dialysis in the HEMO study patients was coming from the ECF.

In our estimates, we assumed that the postdialysis ECF was $1 / 3$ of the total body water. In the data of Ozturk et al. [15] cited earlier, this percentage was somewhat higher, averaging around $43 \%$. It is also possible that in the HEMO study, the urea distribution volume

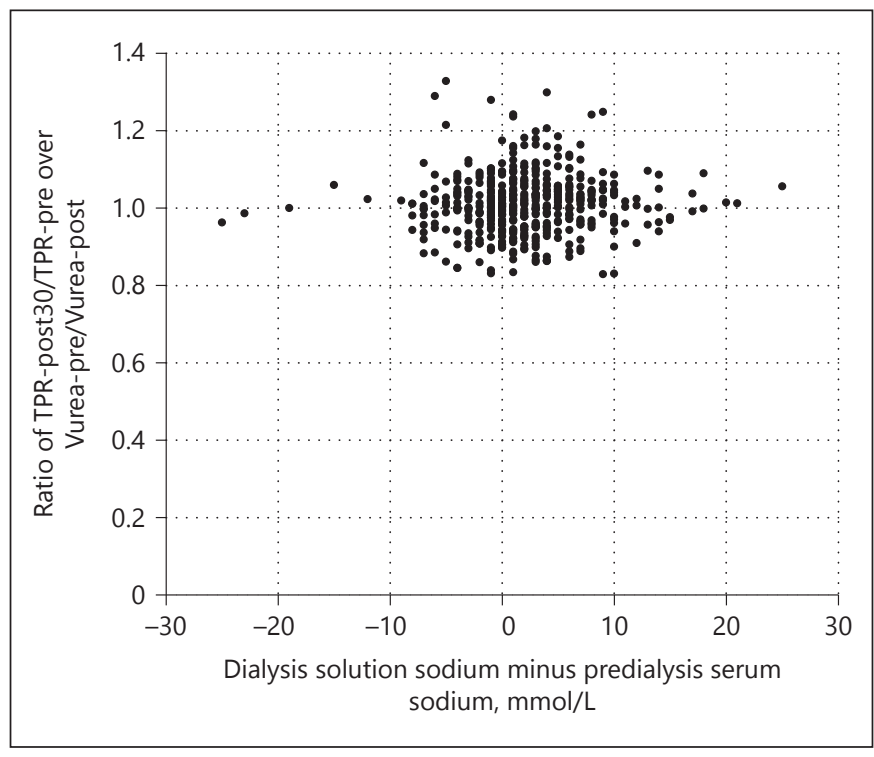

Fig. 4. Impact of dialysate to serum sodium gradient on the ratio of the change in total protein to the change in urea distribution volume ( $n=493$ treatments, 488 unique individuals).

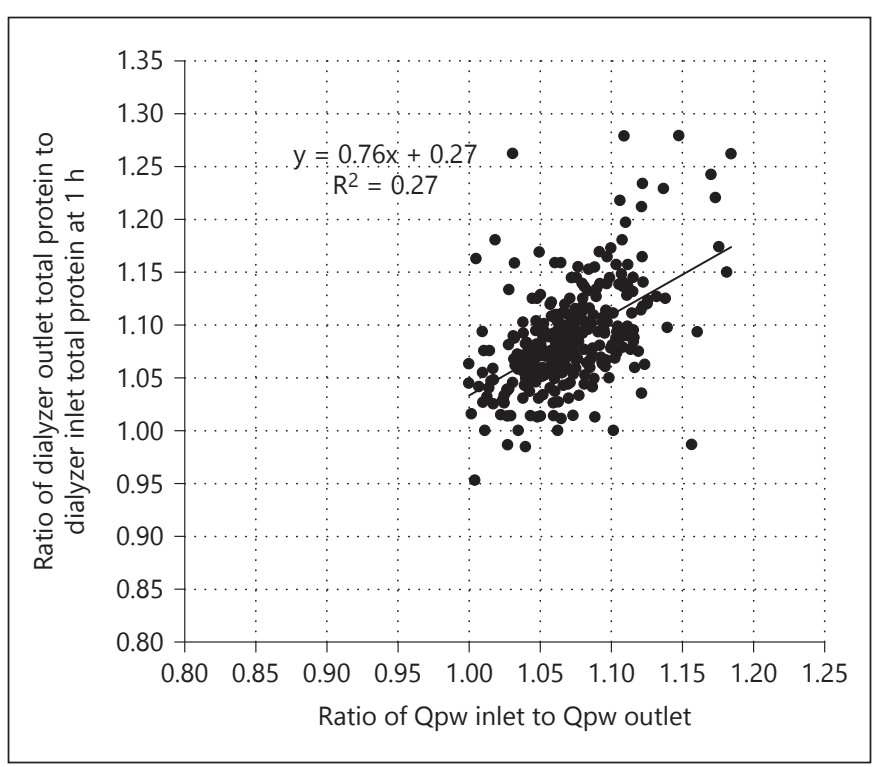

Fig. 5. Relationship between the ratio of dialyzer outlet to inlet total protein concentration, plotted on the vertical axis, to the ratio of calculated plasma water dialyzer inflow (Qpw inlet) to outflow (Qpw outlet), at $1 \mathrm{~h}$ into dialysis.

somewhat underestimated the total body water, in that the ratio of modeled postdialysis urea volume to the volume estimated by the Watson equation [16] was around 0.89 . If one uses the Watson volume estimate for postdialysis total body water in the HEMO Study patients, 
the value would increase from 30 to $34 \mathrm{~L}$, and if one then also used an estimate of postdialysis ECF/TBW ratio of 0.43 , the mean postdialysis ECF would be $14.6 \mathrm{~L}$. In such a scenario, assuming all water was coming from the ECF, the contraction of the ECF would be $(14.6+$ $2.8) / 14.6=1.19$, or $19 \%$ instead of the $28 \%$ figure discussed above. Still, this is markedly higher than the observed $9-10 \%$ increase in serum total protein. Removal of some fluid from the intracellular volume could account for the lower than expected increase in serum total protein, and an equally and perhaps more plausible explanation is that the plasma volume most likely contracted to a lesser degree than the ECF in the course of ultrafiltration.

Although no information about dialysis solution glucose was included in the HEMO Study archive, the study was done during a period in the United States when dialysis solution contained $200 \mathrm{mg} / \mathrm{dL}$ glucose. This was higher than the $100 \mathrm{mg} / \mathrm{dL}$ glucose concentration that was commonly used in Europe at the time, and higher than what is now commonly used in the United States. It is possible that in the HEMO study, more fluid was removed during ultrafiltration from the intracellular volume than expected because the $200 \mathrm{mg} / \mathrm{dL}$ dialysis solution glucose levels were higher than the glucose level in the serum, and this difference in glucose concentrations resulted in the osmotic shift of fluid from the ICF to the ECF during treatment. For example, Schneditz et al. [17] showed that the infusion of hypertonic glucose during dialysis results in a transient increase in plasma volume. However, 2 reports suggest that the higher dialysis solution used in the HEMO study might not have impacted volume shifts. In the paper by Ozturk et al. [15] cited earlier, ICF and ECF changes by bioimpedance were compared during dialysis using 0 or $200 \mathrm{mg} / \mathrm{dL}$ glucose dialysis solution, and the relative decreases in ICF and ECF were not different. Furthermore, our results are similar to those reported by Minutolo et al. [18], who studied changes in hemoglobin and serum total protein as a result of ultrafiltration during dialysis, including the 2-h period after dialysis. In their patients, from whom they removed $4 \%$ body weight over a 4 -h treatment, the serum total protein levels increased markedly during dialysis, more so in the group with higher predialysis hemoglobin values, but by $2 \mathrm{~h}$ after dialysis, the average ratio of serum total protein relative to the predialysis value was approximately 1.11 , close to that found in the HEMO study patients. In that study, the dialysis solution glucose concentration used was $100 \mathrm{mg} / \mathrm{dL}$ (Minutolo et al. [18], personal communication).
Movilli et al. [19] examined the changes in plasma volume as a result of dialysis, as a function of antecedent interdialytic interval, and found that during the long (3-day) interval, the increase in blood volume (measured as change in blood hemoglobin) was unusually large. This is opposite to what one would expect based on Guyton's analysis of the relation between plasma volume and the ECF, in which the increase in plasma volume would become attenuated after the ECF volume increased beyond a certain point [20]. In our HEMO dataset, the day of dialysis was available, and so we were able to examine changes in serum total protein in the first-of-week (Monday and Tuesday) sessions with the midweek and end-of-week treatments. In our data, the duration of the interdialytic interval had no effect on the ratio of change in serum total protein to the change in total body water. However, the amount of fluid removed during the weekend treatments was only 3.0 vs. $2.6 \mathrm{~L}$ during the midweek and end-week treatments; so perhaps a sufficient weekend volume overload signal was not present in the HEMO study patients to effect a sufficient difference in predialysis volume status to impact vascular refilling.

High-flux dialysis might be causing some loss of total protein, resulting in a lower than expected increase in total protein over the course of dialysis due to ultrafiltration. In high-flux vs. low-flux treatments, we compared the ratio of the increase in total protein at 30 -min postdialysis to the predialysis value, with the calculated ratio change in total body water. The median ratio in the low-flux treatments 1.01 , whereas it was 0.99 in the high-flux arm. Although this difference was significant $(p=0.021)$, the amount of difference was trivial, suggesting that the amount of protein removal during high-flux dialysis could not account for the lower than expected increase in total protein due to fluid removal.

As it was possible that the laboratory testing method for total protein was being affected by changes in serum composition due to dialysis, we examined the change in total protein concentration in the dialyzer outlet versus inlet, which was available in samples obtained $1 \mathrm{~h}$ into dialysis. The change in serum composition in the dialyzer outlet would more than mimic any change occurring in the serum during the course of dialysis. The change in serum total protein from dialyzer blood inlet to blood outlet corresponded to the calculated change in plasma water flow (as a ratio) from inlet to outlet due to fluid removal. These findings argue against an analytical artefact on measurement of 
total protein due to serum changes as the result of dialysis.

In the second part of our study, we examined the effect of a sodium gradient between dialysis solution and predialysis serum sodium on the relative change in serum total protein level. The dialysis solution to predialysis serum sodium gradient associated very convincingly with changes in postdialysis versus predialysis serum sodium. The exact point where dialysate sodium would result in a net zero diffusive transport of sodium during dialysis is affected by Donnan equilibrium, as well as the relation of plasma water sodium to plasma sodium level. Also, dialysis solution sodium used in these analyses was the nominal level, and the nominal level has been shown to be different from the measured value [21]. However, the HEMO Study dataset included patients in whom either large positive or large negative sodium gradients were present and there was no detectable impact of a sodium gradient on the magnitude of the increase in serum total protein concentration during dialysis relative to the calculated change in total body water. Hence, the concept that the sodium gradient might affect the body compartment from which fluid is withdrawn was not supported by our data. This does not mean that the dialysate to serum sodium gradient did not alter the distribution of fluid between the intracellular and extracellular compartments [15]. Because ICF and ECF volumes were not measured separately, fluid shifts between these compartments may well have been induced by dialysate-to-serum sodium gradients.

There are 2 additional wrinkles in this. It is assumed that during low-flux dialysis, at least, the total amount of protein in the plasma space is constant throughout dialysis. In fact, studies in large animals (splenectomized sheep) subjected to hemorrhage emphasize the role of lymphatic refilling to help restore plasma volume [22]. The lymph contains substantial amounts of protein, measured to be $66 \%$ as much as plasma in the study cited above [22], although it may be somewhat lower; being $37 \%$ in lymph obtained from the subcutaneous tissue of rabbits [23]. Thus, the amount of total protein in the plasma may actually increase slightly over the course of a 4-h low-flux dialysis due to augmented entry of lymphatic fluid. The second wrinkle is the documented shift of blood from the splanchnic venous system to the central circulation that occurs during fluid removal in the course of dialysis [24]. Whether the protein concentration of the blood that is transferred from the splanchnic venous system centrally is similar to that in the central circulation has not been well studied. Thus, sophisticated models of plasma volume shifts and vascular refilling [25] that take

Total Protein Concentration and Volume Removal in Hemodialysis most of these factors into consideration might be required for a complete analysis.

One aspect that our data might impact is the calculation of distribution volume of solutes by conventional 2-pool modeling. In the models most widely used, it is assumed that all fluid is removed from the ECF, and also that the water volume of the plasma and ECF are reduced in a 1:1 ratio $[8,9]$. Contraction of plasma volume due to ultrafiltration impacts the calculation of solute distribution volume because the postdialysis serum urea or creatinine value is assumed to be affected by both solute removal and by plasma water concentration due to fluid removal. If the degree of plasma water concentration due to ultrafiltration is overestimated, this will impact the degree of change in postdialysis solute concentration ascribed to removal, and will cause the distribution volume to be underestimated. The details of these calculations are beyond the scope of the present paper, but the overall magnitude of the underestimation, which will vary depending on the amount of fluid removed relative to total body water, and will depend on the solute in question, being trivial for a solute such as urea that is distributed in the total body water, but more substantial for a solute such as beta-2-microglobulin, which has a much smaller volume of distribution.

In summary, our results suggest that after a period of postdialysis equilibration, the degree of contraction of plasma water due to ultrafiltration is similar to the overall contraction of total body water, and substantially greater than the estimated contraction of the ECF. The most likely reason is that more water is removed from the interstitial space than from the plasma, but it may also be, that some water is removed from the intracellular volume. The dialysate-to serum sodium gradient did not seem to impact these findings.

\section{Acknowledgment}

We thank the HEMO study investigators and the National Institute of Diabetes and Digestive and Kidney Diseases (NIDDK) data repository for the data used in this study. The HEMO study was performed by the HEMO study investigators and supported by the NIDDK. This paper was not prepared in collaboration with the investigators of the HEMO study and does not necessarily reflect the opinions or views of the HEMO study or the NIDDK.

\section{Disclosure Statement}

The authors declare that there are no conflicts of interest to disclose. 


\section{References}

1 Van Stone JC, Bauer J, Carey J: The effect of dialysate sodium concentration on body fluid distribution during hemodialysis. Trans Am Soc Artif Intern Organs 1980;26:383386.

-2 Cox-Reijven PL, Kooman JP, Soeters PB, Van der Sande FM, Leunissen KM: Role of bioimpedance spectroscopy in assessment of body water compartments in hemodialysis patients. Am J Kidney Dis2001;38:832-838.

-3 Fisch BJ, Spiegel DM: Assessment of excess fluid distribution in chronic hemodialysis patients using bioimpedance spectroscopy. Kidney Int 1996;49:1105-1109.

-4 Zhu F, Schneditz D, Wang E, Martin K, Morris AT, Levin NW: Validation of changes in extracellular volume measured during hemodialysis using a segmental bioimpedance technique. ASAIO J 1998;44:M541-M545.

5 Chanchairujira T, Mehta RL: Assessing fluid change in hemodialysis: whole body versus sum of segmental bioimpedance spectroscopy. Kidney Int 2001;60:2337-2342.

-6 Yu SJ, Kim DH, Oh DJ, Yu SH, Kang ET: Assessment of fluid shifts of body compartments using both bioimpedance analysis and blood volume monitoring. J Korean Med Sci 2006; 21:75-80.

7 Eknoyan G, Beck GJ, Cheung AK, Daugirdas JT, Greene T, Kusek JW, Allon M, Bailey J, Delmez JA, Depner TA, Dwyer JT, Levey AS, Levin NW, Milford E, Ornt DB, Rocco MV, Schulman G, Schwab SJ, Teehan BP, Toto R; Hemodialysis (HEMO) Study Group: Effect of dialysis dose and membrane flux in maintenance hemodialysis. N Engl J Med 2002; 347:2010-2019.

-8 Greene T, Beck GJ, Gassman JJ, Gotch FA, Kusek JW, Levey AS, Levin NW, Schulman G, Eknoyan G: Design and statistical issues of the hemodialysis (HEMO) study. Control Clin Trials 2000;21:502-525.
-9 Daugirdas JT, Depner TA, Greene T, Silisteanu P: Solute-solver: a web-based tool for modeling urea kinetics for a broad range of hemodialysis schedules in multiple patients. Am J Kidney Dis 2009;54:798-809.

10 Leypoldt JK, Cheung AK, Agodoa LY, Daugirdas JT, Greene T, Keshaviah PR: Hemodialyzer mass transfer-area coefficients for urea increase at high dialysate flow rates. The $\mathrm{He}$ modialysis (HEMO) Study. Kidney Int 1997; 51:2013-2017.

11 Depner TA, Greene T, Daugirdas JT, Cheung AK, Gotch FA, Leypoldt JK: Dialyzer performance in the HEMO Study: in vivo KOA and true blood flow determined from a model of cross-dialyzer urea extraction. ASAIO J 2004; 50:85-93.

12 Daugirdas JT, Greene T, Depner TA, Chumlea C, Rocco MJ, Chertow GM; Hemodialysis (HEMO) Study Group: Anthropometrically estimated total body water volumes are larger than modeled urea volume in chronic hemodialysis patients: effects of age, race, and gender. Kidney Int 2003;64:1108-1119.

13 Lopot F, Nejedlý B, Sulková S: Continuous blood volume monitoring and ultrafiltration control. Hemodial Int 2000;4:8-14.

14 Koomans HA, Geers AB, Mees EJ: Plasma volume recovery after ultrafiltration in patients with chronic renal failure. Kidney Int 1984;26:848-854

-15 Ozturk S, Taymez DG, Bahat G, Demirel R, Yazici H, Aysuna N, Sakar S, Yildiz A: The influence of low dialysate sodium and glucose concentration on volume distributions in body compartments after haemodialysis: a bioimpedance analysis study. Nephrol Dial Transplant 2008;23:3629-3634.

16 Watson PE, Watson ID, Batt RD: Total body water volumes for adult males and females estimated from simple anthropometric measurements. Am J Clin Nutr 1980;33:27-39.
17 Schneditz D, Niemczyk S, Sauseng N, Bachler I, Zierler E, Lackner HK, Hafner-Giessauf H: Osmotic and hemodynamic effects of hypertonic glucose during hemodialysis. ASAIO J 2017;63:824-831.

18 Minutolo R, De Nicola L, Bellizzi V, Iodice C, Rubino R, Aucella F, Stallone C, Nappi F, Avella F, Maione E, Conte G, Di Iorio BR: Intra- and post-dialytic changes of haemoglobin concentrations in non-anaemic haemodialysis patients. Nephrol Dial Transplant 2003;18: 2606-2612.

19 Movilli E, Cancarini GC, Cassamali S, Camerini C, Brunori G, Maffei C, Maiorca R: Inter-dialytic variations in blood volume and total body water in uraemic patients treated by dialysis. Nephrol Dial Transplant 2004;19: 185-189.

20 Guyton: Quantitative Analysis of Body Fluid Regulation. Appendix. 1975, pp 343-347.

21 Ekbal NJ, Consalus A, Persaud J, Davenport A: Reliability of delivered dialysate sodium concentration. Hemodial Int 2016;20(suppl 1):S2-S6

22 Lloyd SJ, Boulanger BR, Johnston MG: The lymphatic circulation plays a dynamic role in blood volume and plasma protein restitution after hemorrhage. Shock 1996;5:416-423.

23 Rutili G, Arfors KE: Protein concentration in interstitial and lymphatic fluids from the subcutaneous tissue. Acta Physiol Scand 1977; 99:1-8.

24 Yu AW, Nawab ZM, Barnes WE, Lai KN, Ing TS, Daugirdas JT: Splanchnic erythrocyte content decreases during hemodialysis: a new compensatory mechanism for hypovolemia. Kidney Int 1997;51:1986-1990.

25 de los Reyes V AA, Fuertinger DH, Kappel F, Meyring-Wösten A, Thijssen S, Kotanko P: A physiologically based model of vascular refilling during ultrafiltration in hemodialysis. J Theor Biol 2016;390:146-155. 